\title{
openheart Incidence, treatment and mortality of new-onset atrial fibrillation patients at the intensive care unit
}

\author{
Maartje S Jacobs (D) , ${ }^{1,2,3}$ Bert Loef, ${ }^{4}$ Auke C Reidinga, ${ }^{4}$ Maarten J Postma, ${ }^{2,3,5}$ \\ Marinus Van Hulst, ${ }^{1,3}$ Robert G Tieleman ${ }^{6,7}$
}

\begin{abstract}
- Additional material is published online only. To view please visit the journal online (http://dx.doi.org/10.1136/ openhrt-2019-001226).
\end{abstract}

To cite: Jacobs MS, Loef B, Reidinga AC, et al. Incidence, treatment and mortality of newonset atrial fibrillation patients at the intensive care unit. Open Heart 2020;7: 001226.

doi:10.1136/

openhrt-2019-001226

MVH and RGT contributed equally.

Received 11 December 2019 Revised 27 January 2020 Accepted 20 February 2020
Check for updates

(C) Author(s) (or their employer(s)) 2020. Re-use permitted under CC BY-NC. No commercial re-use. See rights and permissions. Published by BMJ.

For numbered affiliations see end of article.

Correspondence to Dr Maartje S Jacobs; m.s. jacobs@rug.nl

\section{ABSTRACT}

Objective Critically ill patients admitted to the intensive care unit (ICU) often develop atrial fibrillation (AF), with an incidence of around $5 \%$. Stroke prevention in $\mathrm{AF}$ is well described in clinical guidelines. The extent to which stroke prevention is prescribed to ICU patients with $\mathrm{AF}$ is unknown. We aimed to determine the incidence of new-onset AF and describe stroke prevention strategies initiated on the ICU of our teaching hospital. Also, we compared mortality in patients with new-onset AF to critically ill patients with previously diagnosed AF and patients without any AF.

Methods This study was a retrospective cohort study including all admissions to the ICU of the Martini Hospital (Groningen, The Netherlands) in the period 2011 to 2016. Survival analyses were performed using these real-world data.

Results In total, 3334 patients were admitted to the ICU of whom 213 patients (6.4\%) developed new-onset AF. 583 patients (17.5\%) had a previous AF diagnosis, the other patients were in sinus rhythm. In-hospital mortality and 1-year mortality after hospital discharge were significantly higher for new-onset AF patients compared with patients with no history of AF or previously diagnosed AF. At hospital discharge, only $56.3 \%$ of the new-onset AF-patients eligible for stroke prevention received an anticoagulant. Anticoagulation was not dependent on $\mathrm{CHA}_{2} \mathrm{DS}_{2}$-VASc score or other patient characteristics. An effect of anticoagulative status on mortality was not significant.

Conclusion AF is associated with increased mortality in critically ill patients admitted to the ICU. More guidance is needed to optimise anticoagulant treatment in critically ill new-onset AF patients.

\section{INTRODUCTION}

Stroke prevention in atrial fibrillation $(\mathrm{AF})$ is well described in clinical guidelines. The consensus is that oral anticoagulation should be initiated for stroke prevention in $\mathrm{AF}$ to improve outcomes related to stroke and mortality. ${ }^{12}$ Evidence on stroke prevention in critically ill patients is limited. ${ }^{3-5}$ Critically ill patients admitted to the intensive care unit (ICU) often develop AF, with an incidence around 5\% though this could rise to

\section{Key questions}

What is already known about this subject?

- Critically ill patients admitted to the intensive care unit (ICU) often develop atrial fibrillation (AF), with an incidence around $5 \%$ though this could rise to nearly $50 \%$ in specific subgroups. There is no clear consensus on which anticoagulative treatment is most appropriate to treat new-onset AF in critically ill patients,

What does this study add?

- In-hospital mortality and 1-year mortality was significantly higher for new-onset atrial fibrillation patients compared with patients with no history of AF or previously diagnosed AF. Only $25.3 \%$ of the new-onset AF patients eligible for stroke prevention received antiocoagulation at the ICU and this rose to over half at hospital discharge. An effect of anticoagulative status on mortality could not be demonstrated.

How might this impact on clinical practice?

- This study illustrates the lack of evidence, guidance and consensus on treatment in this specific patient group of critically ill new-onset AF patients. More research could help to optimise clinical guidelines on stroke prevention in this group of patients.

nearly $50 \%$ in patients with severe sepsis. ${ }^{4-9}$ Acute pathophysiological changes such as inflammation, atrial oxidative stress, a high symptomatic tone and volume overload could be provoking factors for new-onset $\mathrm{AF}$ in critically ill patients. ${ }^{5}{ }^{10} \mathrm{New}$ onset of AF can be self-terminating in the critically ill phase though it could also be provocative for developing permanent AF. Evidence suggests that new-onset $\mathrm{AF}$ is associated with a higher mortality in critically ill patients admitted to the ICU. ${ }^{91112}$ Since there is no clear consensus on which anticoagulative treatment is most appropriate to treat newonset AF in critically ill patients, we aimed to determine the incidence of new-onset $\mathrm{AF}$ in a retrospective cohort study and analysed the 
anticoagulation strategies that were initiated on the ICU of our teaching hospital. Also, we compared mortality in patients with new-onset AF compared with ICU patients without $\mathrm{AF}$ and also compared mortality in the new-onset AF patients to mortality in patients with previously diagnosed AF. Finally, we explored whether there is a relation between anticoagulation therapy and mortality in the new-onset AF patients.

\section{MATERIALS AND METHODS \\ Patients and procedure}

The study was a retrospective cohort study including all hospitalisations to the ICU of the Martini Hospital (Groningen, The Netherlands) between 2011 and 2016.

Need for informed consent was waived by this Medical Ethics Committee. The format of the Minimal Data Set (MDS) of the National Intensive Care Evaluation (NICE) registry, a registry with all available data from all ICUs in the Netherlands, ${ }^{13}$ was used to collect all primary data and to determine the population size at our ICU. The data collected in the NICE registry was supplemented with additional data from the electronic health records (EHR) that was not captured in the NICE registry. This data consisted of hospital data from outside the ICU and some more specific data on medication use. To retrieve additional data from EHR, an interface (CTcue; CTcue BV; Amsterdam, The Netherlands) was used for a keyword text search for 'atrial fibrillation' and related synonyms for all patients admitted to the ICU within the research period. All data from the interface were matched with the hospital specific data in the format of the NICE MDS on the unique patient hospital identification number. The ICU hospital discharge letter was the primary source to determine if there was any AF diagnosed during ICU admission. Medical letters from the cardiology department prior to the ICU admission, if available, were also analysed to determine a prior AF diagnosis. Furthermore, the ECG database containing short 12-lead ECG recordings (MUSE, General Electric) was used to screen for ECGs with AF during the period of ICU admission. Automatic ECG AF diagnosis was confirmed by a cardiologist (RGT). The data was pseudonymised in the final data set. The diagnosis $\mathrm{AF}$ was denoted as present or absent on ICU admission to discriminate between no AF, known AF (pre-existing) and new-onset AF. Known AF also included patients with paroxysmal $\mathrm{AF}$ and patients with periods of sinus rhythm. Only the first ICU admission within the study period was used to determine the AF-related medical background and if $\mathrm{AF}$ was incident.

\section{Patient and public involvement}

Patients were not involved in the design and conduct of this study.

\section{Outcomes}

AF was confirmed with a 12-lead ECG. Categories of AF were defined as (1) 'No AF' with no previous AF diagnosed and no new diagnosis, (2) 'Known AF' with the diagnosis confirmed before ICU admission and (3) 'Newonset AF' with a first diagnosis during the ICU admission. Mortality was defined by checking if a date of decease was registered in the NICE MDS for decease during ICU admission and by checking if a date of decease was registered within the national database that includes the unique 'citizen service number'. Mortality was determined within 360 days after hospital discharge following the ICU admission. In-hospital mortality was scored separately and defined as death by any cause that took place between ICU admission and the associated hospital discharge. Mortality for the maximum follow-up was also measured but not used for comparative survival analyses because of the high percentage of censored patients and the non-proportionality of the survival curves.

\section{Covariates}

Demographic data included age and sex category. Comorbidities present on admission were registered for all newonset $\mathrm{AF}$ patients with the diagnosis mentioned in the discharge letter. The registered comorbidities included heart failure, hypertension, diabetes, prior stroke/TIA and vascular disease to calculate the $\mathrm{CHA}_{2} \mathrm{DS}_{2}$-VASc score. The need for stroke prevention was determined with the $\mathrm{CHA}_{2} \mathrm{DS}_{2}$-VASc score: men with a score of 1 or higher and women with a score of 2 or more were classified as eligible for stroke prevention. A minimal scoring method was used to calculate the bleeding risk through the HAS-BLED score, by adding information on renal disease, liver disease (cirrhosis), prior bleeding, alcohol use and medication usage predisposing to bleeding (non-steroidal anti-inflammatory drugs and platelet inhibitors). Variables scored on discharge from the ICU, discharge from the hospital and 6 and 12 months after hospital discharge were only included for all patients with new-onset AF documented in the ICU discharge letter. The included variables were: the use of an anticoagulant (vitamin K oral anticoagulants, non-vitamin K antagonist, oral anticoagulant (apixaban, dabigatran, edoxaban or rivaroxaban) or a low-molecular-weight heparin with a daily dose $>7600$ I.E.), use of medication for rate and/ or rhythm control (amiodarone, beta-blocker, digoxin, verapamil) and whether the patient was in sinus rhythm.

\section{Statistical analyses}

Descriptive analysis for patient characteristics included mean \pm SD or median and range for normal and nonnormally distributed data, respectively. Categorical data were described as number and percentage. KaplanMeier survival curves were used to estimate the median survival for the following status categories: (1) no AF, (2) known AF, (3) new-onset AF patients. Patients that died in the hospital were excluded from the survival analysis and are listed separately. For new-onset AF patients, subanalyses were performed on 1-year survival based on AF status. Status categories were 1:1 matched with newonset patients using the APACHE III (Acute Physiology and Chronic Health Evaluation) score on ICU admission 
(match tolerance 0.001). The APACHE III score was used for propensity score matching to balance the groups on survival since this score has a good performance to predict mortality. Mean survival was compared for different status categories using the log-rank test at a twosided statistical significance level of $p=0.05$. An exploratory analysis was performed to determine if there were differences in characteristics between the new-onset AF patients in whom anticoagulation was initiated and the patients in whom anticoagulation was not started before hospital discharge. Comparison was performed with an independent samples t-test at a two-sided statistical significance level of $\mathrm{p}=0.10$, categorical variables were compared using a $\chi^{2}$ test. A multiple logistic regression analysis on mortality could be performed if there were significant differences $(p<0.10)$ in patient characteristics between the two new-onset AF groups based on anticoagulation status.

\section{RESULTS}

A total of 3334 unique patients were identified with an ICU admission between $1^{\text {st }}$ of January 2011 and $31^{\text {st }}$ of December 2016. In 2538 patients $(76.1 \%)$ there was no AF documented. A total of 796 patients $(23.9 \%)$ had any form of AF. AF was already known in $17.5 \%$ of the patients, and $6.4 \%(\mathrm{n}=213)$ had new onset $\mathrm{AF}$ during the ICU admission. In $1.6 \%(\mathrm{n}=54)$ of the patients, new-onset $\mathrm{AF}$ was not documented in the ICU discharge letter, and reasons for starting or withholding anticoagulation could not be retrieved. All patient numbers are summarised in online supplementary figure 1.

The median age of the total population was 69 years and $42.8 \%$ was female. The median length of stay (LOS) at the ICU was 2 days for the overall population and median total hospital LOS was 10 days. The majority of the patients $(55 \%)$ were admitted to the ICU for a medical reason. Table 1 shows that the three groups of AF patients had significant differences in patient characteristics. Patients with new-onset AF more often had a medical indication for ICU admission, longer LOS at the ICU, longer LOS at the hospital, a higher APACHE II and III score compared with the other two patient groups. Patients with known $\mathrm{AF}$ and new-onset $\mathrm{AF}$ were older than patients with no AF.

\section{Treatment strategies for atrial fibrillation: anticoagulation and rate/rhythm control}

Based on the $\mathrm{CHA}_{2} \mathrm{DS}_{2}$-VASsc score, stroke prevention was indicated in $94.3 \%$ of the patients with new-onset $\mathrm{AF}$ and only $25.3 \%$ of these eligible patients received anticoagulation during their ICU stay. At hospital discharge, 56.3\% of the eligible patients received an anticoagulant. There were also seven patients $(5.2 \%)$ that were initiated on antiplatelet therapy for their AF before being leaving the hospital. There were no differences in key patient characteristics between the new-onset AF patient group that initiated an anticoagulant before hospital discharge and the new-onset patients that did not initiate an anticoagulant (tested variables: age, sex category, reason for ICU admission (medical versus surgical), ICU LOS, APACHE III score, mean $\mathrm{CHA}_{2} \mathrm{DS}_{2}$-VASc score and mean HASBLED score). When discharged from the ICU, 39.6\% of the patients still had AF with $55.1 \%$ using rate/rhythm control medication. Almost half of the patients had an unknown rhythm at hospital discharge, and in $60.7 \%$ of the patients it was mentioned that they continued having

\begin{tabular}{|c|c|c|c|c|c|c|c|c|}
\hline \multirow{2}{*}{$\begin{array}{l}\text { Characteristic } \\
\text { Age, median (range) }\end{array}$} & \multicolumn{2}{|c|}{$\begin{array}{l}\text { Total population } \\
(\mathrm{n}=3334)\end{array}$} & \multicolumn{2}{|c|}{$\begin{array}{l}\text { No AF } \\
(n=2538)\end{array}$} & \multicolumn{2}{|c|}{$\begin{array}{l}\text { AF known } \\
(n=583)\end{array}$} & \multicolumn{2}{|c|}{ New-onset $\mathrm{AF}^{\star}(\mathrm{n}=213)$} \\
\hline & 69 & (12-99) & $67 \dagger \ddagger$ & $(12-99)$ & $7 \dagger$ & $(31-99)$ & $76 \ddagger$ & $(41-97)$ \\
\hline Female, n (\%) & 1426 & $(42.8)$ & 1100 & (43.3) & 251 & $(43.1)$ & 75 & $(35.2)$ \\
\hline APACHE II, median (range) & 15 & $(1-50)$ & $14 \neq \dagger$ & $(1-50)$ & $18+\S$ & $(3-44)$ & $19 \neq \S$ & $(5-46)$ \\
\hline APACHE III median (range) & 57 & $(6-200)$ & $52 \ddagger \dagger$ & $(6-200)$ & $70 \dagger \S$ & $(17-182)$ & $75 \ddagger \S$ & $(26-191)$ \\
\hline LOS ICU, median (range) & 2 & $(0.1-100)$ & $2 \ddagger \dagger$ & $(0.1-85)$ & $2+\S$ & $(0.1-100)$ & $7 \ddagger \S$ & $(0.3-95)$ \\
\hline LOS hospital, median (range) & 10 & $(0.1-196)$ & 9ł† & $(0.1-128)$ & $11 \dagger \S$ & $(0.1-196)$ & $16 \mp \S$ & $(0.3-96)$ \\
\hline \multicolumn{9}{|l|}{ Reason for ICU admission, n (\%) } \\
\hline Medical & 1834 & $(55.0)$ & $1358+\dagger$ & $(53.5)$ & $345 \dagger \neq \S$ & $(59.2)$ & $131 \ddagger \S$ & $(62.7)$ \\
\hline Urgent surgery & 493 & $(14.8)$ & $354 \pm \dagger$ & $(14.0)$ & $92 \dagger \neq \S$ & (15.8) & $47 \ddagger \S$ & (22.5) \\
\hline Planned surgery & 1001 & $(30.0)$ & 824ł† & $(32.5)$ & $146 \dagger \neq \S$ & $(25.0)$ & $31 \neq \S$ & (14.8) \\
\hline Missing & & & 2 & $(<0.01)$ & & & 4 & $(1.2)$ \\
\hline
\end{tabular}

*The group 'new-onset AF' includes documented and non-documented AF.

†Significant difference between no AF group and known AF group $(p<0.05)$.

$\ddagger$ Significant difference between new-onset AF group and no AF group $(p<0.05)$.

$\S$ Significant difference between new-onset AF group and known AF group $(p<0.05)$.

AF, atrial fibrillation; APACHE, Acute Physiology and Chronic Health Evaluation; ICU, intensive care unit; LOS, length of stay. 
Table 2 Atrial fibrillation treatment strategy in rate/rhythm control and anticoagulant use at the intensive care unit and at hospital discharge for new-onset atrial fibrillation patients with AF documented in the discharge letter $(n=159)$

\begin{tabular}{|c|c|}
\hline \multicolumn{2}{|l|}{ Characteristic } \\
\hline $\mathrm{CHA}_{2} \mathrm{DS}_{2}$-VASc score, median $(95 \% \mathrm{Cl})$ & 3 (3 to 4) \\
\hline HAS-BLED score, median $(95 \% \mathrm{Cl})$ & 2 (2 to 3$)$ \\
\hline \multicolumn{2}{|l|}{ Rhythm/rate control, n (\%) } \\
\hline \multicolumn{2}{|l|}{ Initiated at the ICU $(n=159)$} \\
\hline Amiodarone IV administered & $109(68.6)$ \\
\hline Digoxin administered & $142(89.3)$ \\
\hline Verapamil administered & $0(0.0)$ \\
\hline Beta-blocker administered & $50(31.4)$ \\
\hline $\begin{array}{l}\text { Oral rate/rhythm control medication at ICU } \\
\text { discharge* }^{*}\end{array}$ & $87(55.1)$ \\
\hline AF unresolved & $63(39.6)$ \\
\hline \multicolumn{2}{|l|}{ Hospital discharge $(n=135)$} \\
\hline Rhythm/rate control medication & $87(64.4)$ \\
\hline AF unresolved & $82(60.7)$ \\
\hline Unknown rhythm & $63(46.7)$ \\
\hline \multicolumn{2}{|c|}{ Anticoagulant initiated, $\mathrm{n}$ (total $\% ; \%$ of eligible patients) } \\
\hline Initiated at the ICU $(n=159)$ & $43(27.0 ; 25.3)$ \\
\hline Therapeutic LMWH & $36(22.6)$ \\
\hline VKA & $5(3.1)$ \\
\hline NOAC & $2(1.3)$ \\
\hline Hospital discharge $(n=135)$ & $68(50.4 ; 56.3)$ \\
\hline Therapeutic dose LMWH & $7(5.2)$ \\
\hline VKA & $38(28.1)$ \\
\hline NOAC & $23(17.0)$ \\
\hline One year after hospital discharge $(n=99)$ & $36(36.4 ; 38.3)$ \\
\hline
\end{tabular}

${ }^{*}$ Oral rate/rhythm control included: amiodarone, beta-blockers, digoxin, verapamil.

AF, atrial fibrillation; ICU, intensive care unit; IV, intravenously; $\mathrm{LMWH}$, low-molecular-weight heparin; NOAC, non-vitamin $\mathrm{K}$ antagonist oral anticoagulant; VKA, vitamin $\mathrm{K}$ oral antagonist.

$\mathrm{AF}$ while $64.4 \%$ of patients were using rate/rhythm control drugs at discharge. The results for the new-onset AF patients are summarised in table 2.

\section{Mortality}

In-hospital mortality was $9.8 \%, 18.9 \%$ and $20.3 \%$ within the subpopulation with no AF, with known $\mathrm{AF}$ and with new-onset AF. The median follow-up was 1431 days. Total mortality during the whole follow-up, including in-hospital mortality, was $35.3 \%, 57.1 \%$ and $57.3 \%$ in the subpopulation with no AF, with known $\mathrm{AF}$ and with newonset AF, respectively. One-year mortality, not including in-hospital mortality, was $13.5 \%, 25.0 \%$ and $26.0 \%$ in the subpopulation with no AF, with known AF and with newonset AF, respectively (see figure 1).

Propensity score matching was applied to balance the groups of new-onset $\mathrm{AF}$, known $\mathrm{AF}$ and no $\mathrm{AF}$ with regard to the predicted mortality (see Method section). The groups were propensity score matched on APACHE III score. Patient characteristics of the matched groups are summarised in table 3. The median APACHE III and range are more balanced compared with the total subpopulation (see table 1).

In the propensity matched groups, the in-hospital mortality was $5.3 \%$ for patients with no AF and $7.2 \%$ in the patients with known AF. The in-hospital mortality for the new-onset $\mathrm{AF}$ group was the same as previously mentioned $(20.3 \%)$ since the whole group is used in the propensity score matching. The mortality within the first year after being discharged from the hospital alive was $4.6 \%$ in patients with no AF, $11.6 \%$ in the patients with known $\mathrm{AF}$ and $26.0 \%$ in patients with new-onset $\mathrm{AF}$ (Figure 2).

The unadjusted estimated mean survival within the total study period was 1334 days for all patients, median survival was 1603 days. For the patients with no AF this estimated mean survival was 1433 days, 975 days for patients with known $\mathrm{AF}$ and for new-onset $\mathrm{AF}$ patient the estimated mean survival was 1033 days. When also adding in-hospital mortality to the overall survival curve, the mortality rate was proportional in all groups and converged after approximately 5 years of follow-up (see online supplementary figure 2). In-hospital mortality was significantly higher in patients with any form of AF compared with patients with no AF ( $p<0.01$, survival curve not shown). In-hospital mortality was significantly higher for new-onset AF patients compared with patients with no AF $(\mathrm{p}<0.01)$ but not higher compared with patients with known $\mathrm{AF}$ ( $\mathrm{p}=0.658)$ for the non-matched groups. In the propensity matched groups, in-hospital mortality was significantly higher in the new-onset $\mathrm{AF}$ group compared with no $\mathrm{AF}$ and known $\mathrm{AF}$ (both $\mathrm{p}<0.01$ ).

Mean survival for patients with no AF, with known AF and new-onset AF was 347 days, 336 days and 295 days, respectively, when censored at a maximum of 360 days. Survival was significantly different for these groups $(p<0.01)$. Survival was significantly different for no AF versus new-onset $A F$ groups $(p<0.01)$. Mean survival in new-onset AF patients that was documented during ICU admission was not significantly different for patients that used an anticoagulant (301 days) or those who did not use an anticoagulant (293 days) when discharged from the hospital $(\mathrm{p}=0.701)$.

\section{DISCUSSION}

The incidence of new-onset $\mathrm{AF}$ in the critically ill patients admitted to the ICU was $6.4 \%$ in this study. The incidence found was comparable to other studies, where incidence was generally estimated around $5 \%{ }^{4-7}$ Stroke prevention was indicated in almost $95 \%$ of the newly diagnosed AF patients based on the stroke risk although only $26.7 \%$ of these eligible patients received anticoagulation during their ICU stay. At hospital discharge, $56.3 \%$ of the eligible patients received an 


\section{Survival Functions Non-matched}

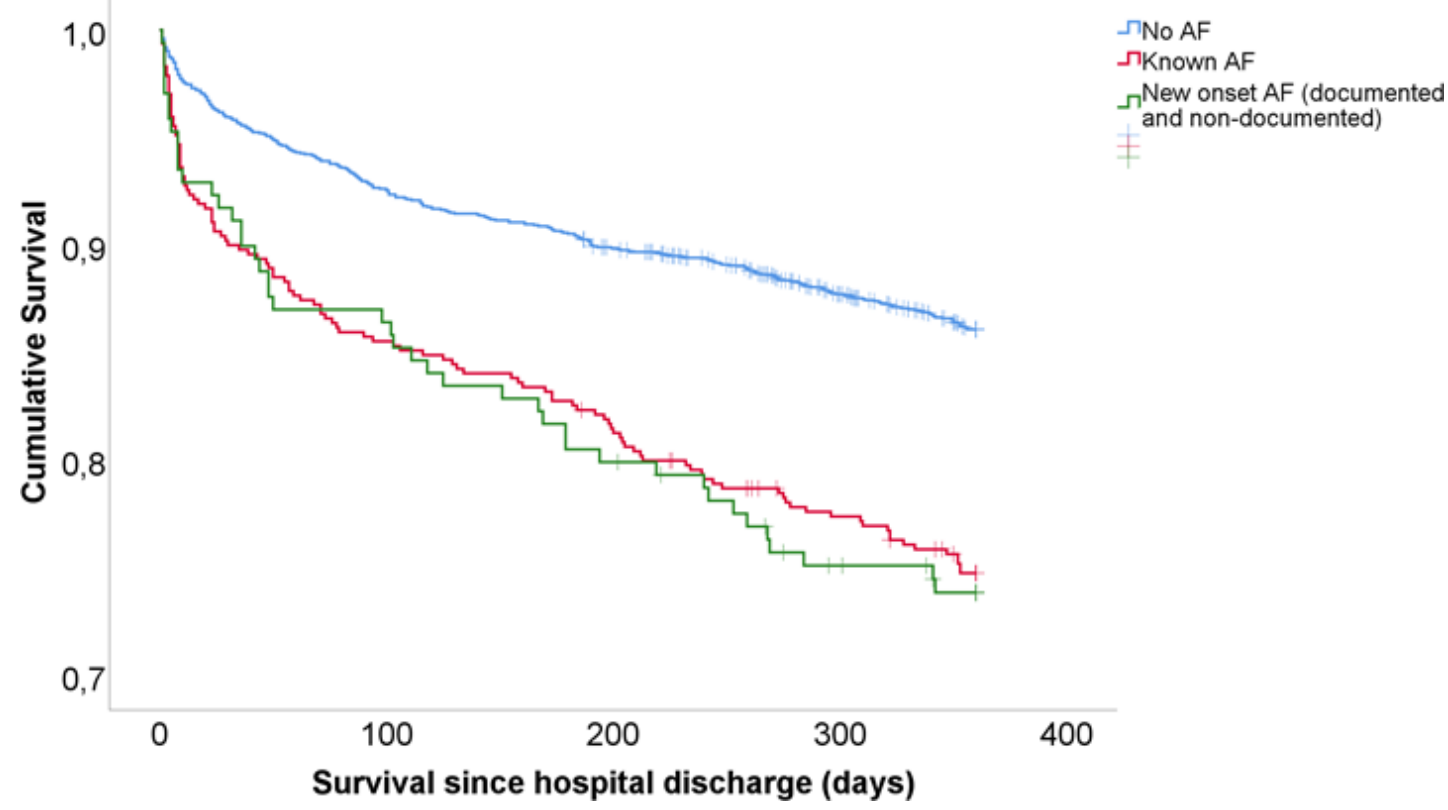

Figure 1 Survival censored at 360 days of follow-up after hospital discharge for all patients $(n=3334)$, stratified by all atrial fibrillation category. A vertical line in the curve represents a censored patient. AF, atrial fibrillation.

anticoagulant. Reasons not to initiate anticoagulation included poor prognosis, recent surgery with perceived increased risk of bleeding or postponement to the post-hospitalisation period for a cardiologist to decide. Although this was not studied, an epidural could also be a reason to postpone anticoagulation. There were no clear differences in patient characteristics between patient in whom anticoagulation was started versus those who did not receive anticoagulants. This illustrates the lack of evidence and guidance on treatment in this specific patient group of critically ill new-onset $\mathrm{AF}$ patients. Other studies also reported percentages of $70.4 \%$ and $69.6 \%$ for $\mathrm{AF}$ patients that did not receive anticoagulation at the ICU. ${ }^{3} 12$

Spontaneous restoration of normal sinus rhythm was mentioned as a reason not to initiate any anticoagulant therapy. Often this was the case if the duration of the

Table 3 Subgroup patient characteristics of intensive care unit admitted patients by subgroups within the period 2011 to 2016 propensity matched on atrial fibrillation status

\begin{tabular}{llll}
\hline Characteristic & $\begin{array}{l}\text { No AF } \\
(\mathbf{n = 2 0 8})\end{array}$ & $\begin{array}{l}\text { AF known } \\
(\mathbf{n = 1 9 5 )}\end{array}$ & $\begin{array}{l}\text { New-onset } \\
\mathbf{A F} \\
\mathbf{( n = 2 1 3 )}\end{array}$ \\
\hline Age, median (range) & $70(20-93)$ & $76(31-94)$ & $76(41-97)$ \\
\hline Female, $\mathrm{n}$ (\%) & $90(43.2)$ & $90(46.2)$ & $75(35.2)$ \\
\hline APACHE II, median (range) & $18(3-49)$ & $18(7-44)$ & $19(5-46)$ \\
\hline APACHE III, median (range) & $75(25-191)$ & $74(26-126)$ & $75(26-191)$ \\
\hline LOS ICU, median (range) & $3(0.2-76.4)$ & $3(0.1-100)$ & $7(0.3-95)$ \\
\hline LOS hospital, median (range) & $13(0.1-128)$ & $13(0.1-196)$ & $16(0.3-96)$ \\
\hline
\end{tabular}

New-onset AF includes documented and non-documented AF.

AF, atrial fibrillation; APACHE, Acute Physiology and Chronic Health

Evaluation; ICU, intensive care unit; LOS, length of stay. arrhythmia was limited to less than 1 day. The perception seems to exist that the need of anticoagulation depends on a patient's symptomatic status. In general, evidence suggests that the stroke risk is still increased after restoration of sinus rhythm. ${ }^{81415}$ However, it can be debated if this principle also applies to AF that developed in the critically ill phase since there could be provoking factors for developing an arrhythmia. ${ }^{510}$ A recent study showed that there was no difference in stroke occurrence after 5 years follow-up between patients with new-onset postoperative AF following coronary artery bypass grafting (CABG) and patients without new-onset postoperative AF following CABG. ${ }^{16}$ Another study found that the thromboembolic risk was lower in post-CABG new-onset AF patients compared with matched non-valvular AF patients (HR 0.67; $95 \%$ CI 0.55 to 0.81 ). The risk of thromboembolism was also not significantly higher in patients with postoperative new-onset $\mathrm{AF}$ compared with patients that did not develop AF after CABG surgery. ${ }^{17}$ These findings might indicate that the thromboembolic risk of new-onset $\mathrm{AF}$ patients shouldn't be regarded equivalent to the risk of non-valvular AF patients. Sinus rhythm was restored in $60 \%$ of the patients at discharge from the ICU, this dropped to around $40 \%$ at hospital discharge though this could be an underestimate since the rhythm was unknown in around half of the discharged patients. The percentage of patients that left the ICU in sinus rhythm is comparable to another study that found $82 \%$ of the patients in sinus rhythm. ${ }^{6}$ In-hospital mortality in our study population was comparable to results found in other ICU studies. ${ }^{12} 1819$ Also, overall mortality was comparable to mortality found in other studies. 


\section{Survival Function Matched}

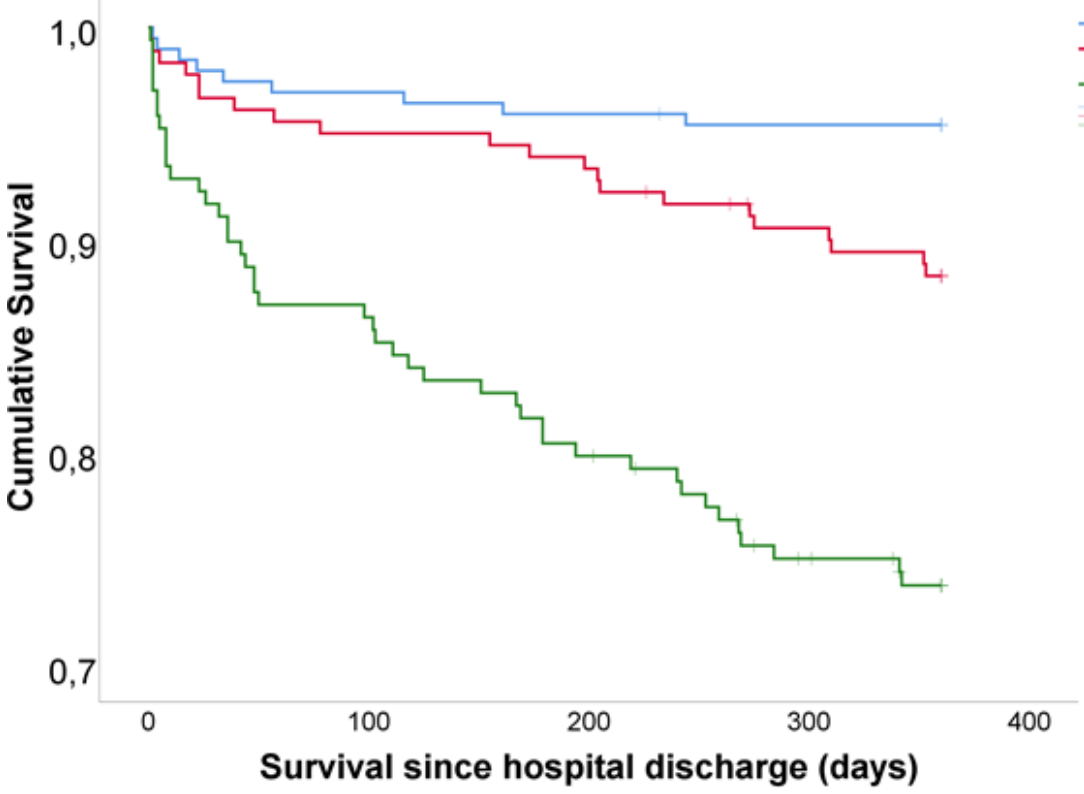

Figure 2 Survival censored at 360 days of follow-up after hospital discharge compared with propensity score matched groups of patients with no atrial fibrillation or known atrial fibrillation or versus patients with new-onset atrial fibrillation $(n=208$, $n=195$ and $n=213$, respectively). A vertical line in the curve represents a censored patient. AF, atrial fibrillation.

New-onset AF patients had a lower survival compared with patients with no AF or previously diagnosed AF, also after propensity score matching. AF is often found to be an (independent) predictor of mortality in critically ill patients. ${ }^{721520}$ Whether the association between AF and hospital mortality is independent could be debated since many factors can influence mortality. ${ }^{8}$ New-onset AF patients often have a higher LOS and severe sepsis occurs more often. ${ }^{812} 21$

Our study was a single centre study and therefore the results are not by definition representative of a general ICU population. Patient characteristics could be diverse between different ICUs also depending on the type of ICU (medical or surgical). However, when comparing the results of our ICU to that of other Dutch ICUs we found similar results with regard to mortality. ${ }^{19}$ Also, the new-onset AF prevalence was comparable to that found in other ICU studies. ${ }^{4-7}$ Data was retrospectively collected, therefore data can be incomplete and there could be a lack of documentation of AF since data collection was not designed for this research question. The number of patients with new-onset $\mathrm{AF}$ was too small to determine the influence of anticoagulation on survival. This analysis should be considered as an explanatory analysis that was underpowered to draw any firm conclusions. Larger cohorts are needed to see what effect anticoagulation has on mortality and stroke. A final answer on the question whether critically ill patients with new onset AF require anticoagulation therapy should come from a randomised controlled clinical trial. Assuming stroke prevention could reduce mortality by $25 \%$, a power of $80 \%$ and $15 \%$ mortality in the control group, based on numbers for Dutch ICUs, at a significance level of 0.05 , you would need over 1250 patients with new onset AF in both arms of this study. ${ }^{17}$ Based on an incidence of $5 \%$ of new onset AF, this would require an initial data set of 50000 admitted ICU patients.

\section{CONCLUSION}

New-onset AF in critically ill patients is associated with a higher mortality compared with patients with no AF or previously diagnosed AF. There was no effect found for anticoagulative status on mortality based on the results of an exploratory analysis. AF treatment in terms of anticoagulation is not well defined in clinical guidelines and this is reflected in the results that showed less than $60 \%$ of the eligible new-onset AF patients, based on the calculated stroke risk, received anticoagulation before hospital discharge. More evidence is needed to optimise treatment in this specific population and to highlight the importance on long-term outcomes such as mortality and stroke.

\section{Author affiliations}

${ }^{1}$ Department of Clinical Pharmacy and Toxicology, Martini Hospital, Groningen, The Netherlands

${ }^{2}$ Department of Pharmacy, University of Groningen, Groningen Research Institute of Pharmacy, Groningen, Netherlands

${ }^{3}$ Department of Health Sciences, University of Groningen, University Medical Center, Groningen, The Netherlands

${ }^{4}$ Department of Intensive Care, Martini Hospital, Groningen, Netherlands ${ }^{5}$ Department of Economics, Econometrics \& Business, University of Groningen, Faculty of Economics \& Business, Groningen, Netherlands

${ }^{6}$ Department of Cardiology, Martini Hospital, Groningen, Netherlands ${ }^{7}$ Department of Cardiology, University Medical Center Groningen, Groningen, Netherlands 
Contributors MJ, RGT and MvH developed the methods. MJ collected and analysed the data and prepared the first draft of the manuscript. MJ, BL, AR, RGT and $\mathrm{MvH}$ critically reviewed the data and provided overall guidance. MJP reviewed and contributed to the manuscript.

Funding The authors have not declared a specific grant for this research from any funding agency in the public, commercial or not-for-profit sectors.

Competing interests MJ is an employee of Sanofi. The work presented here is not related to this employment and presents a personal opinion in the context of $\mathrm{PhD}$ research. RGT reports grants and personal fees from Boehringer Ingelheim, personal fees from Bayer and personal fees from Pfizer/Bristol Meyer Squibb all outside the submitted work. MJP reports grants and personal fees from various pharmaceutical industries all outside the submitted work. MJP holds stocks in Ingress Health and Pharmacoeconomics Advice Groningen (PAG Ltd).

Patient consent for publication Not required.

Ethics approval This study was approved by the Medical Ethics Committee of the Martini Hospital (Groningen, The Netherlands).

Provenance and peer review Not commissioned; externally peer reviewed.

Data availability statement № data are available. Deindentified patient data is not available for sharing.

Open access This is an open access article distributed in accordance with the Creative Commons Attribution Non Commercial (CC BY-NC 4.0) license, which permits others to distribute, remix, adapt, build upon this work non-commercially, and license their derivative works on different terms, provided the original work is properly cited, appropriate credit is given, any changes made indicated, and the use is non-commercial. See: http://creativecommons.org/licenses/by-nc/4.0/.

ORCID iD

Maartje S Jacobs http://orcid.org/0000-0002-6185-4718

\section{REFERENCES}

1 Kirchhof P, Benussi S, Kotecha D, et al. 2016 ESC guidelines for the management of atrial fibrillation developed in collaboration with EACTS. Eur Heart J 2016;37:2893-962.

2 Lip GYH, Laroche C, Popescu MI, et al. Improved outcomes with European Society of cardiology guideline-adherent antithrombotic treatment in high-risk patients with atrial fibrillation: a report from the EORP-AF General pilot registry. Europace 2015;17:1777-86.

3 Darwish OS, Strube S, Nguyen HM, et al. Challenges of anticoagulation for atrial fibrillation in patients with severe sepsis. Ann Pharmacother 2013;47:1266-71.

4 Yoshida T, Fujii T, Uchino S, et al. Epidemiology, prevention, and treatment of new-onset atrial fibrillation in critically ill: a systematic review. J Intensive Care 2015;3:1-11.
5 Bosch NA, Cimini J, Walkey AJ. Atrial fibrillation in the ICU. Chest 2018:154:1424-34.

6 Kanji S, Williamson DR, Yaghchi BM, et al. Epidemiology and management of atrial fibrillation in medical and noncardiac surgical adult intensive care unit patients. J Crit Care 2012;27:326.e1-8.

7 Klein Klouwenberg PMC, Frencken JF, Kuipers S, et al. Incidence, predictors, and outcomes of new-onset atrial fibrillation in critically ill patients with sepsis. A cohort study. Am J Respir Crit Care Med 2017; 195:205-11.

8 Walkey AJ, Wiener RS, Ghobrial JM, et al. Incident stroke and mortality associated with new-onset atrial fibrillation in patients hospitalized with severe sepsis. JAMA 2011;306:2248-54

9 Meierhenrich R, Steinhilber E, Eggermann C, et al. Incidence and prognostic impact of new-onset atrial fibrillation in patients with septic shock: a prospective observational study. Crit Care 2010;14:R108

10 Engelmann MDM, Svendsen JH. Inflammation in the genesis and perpetuation of atrial fibrillation. Eur Heart J 2005;26:2083-92.

11 Annane D, Sébille V, Duboc D, et al. Incidence and prognosis of sustained arrhythmias in critically ill patients. Am J Respir Crit Care Med 2008:178:20-5.

12 Gupta S, Tiruvoipati R, Green C. Atrial fibrillation and mortality in critically ill patients: a retrospective study. Am J Crit Care 2015;24:336-41.

13 National Intensive Care Evaluation (NICE). Available: www.stichtingnice.nl [Accessed 20th Jan 2019].

14 Champion S, Lefort Y, Gaüzère B-A, et al. CHADS2 and CHA2DS2-VASc scores can predict thromboembolic events after supraventricular arrhythmia in the critically ill patients. J Crit Care 2014;29:854-8.

15 Adderley NJ, Nirantharakumar K, Marshall T. Risk of stroke and transient ischaemic attack in patients with a diagnosis of resolved atrial fibrillation: retrospective cohort studies. $B M J$ 2018;361:k1717.

16 Almassi GH, Hawkins RB, Bishawi M, et al. New-onset postoperative atrial fibrillation impact on 5-year clinical outcomes and costs. $J$ Thorac Cardiovasc Surg 2019;S0022-5223:32774-6.

17 Butt JH, Xian Y, Peterson ED, et al. Long-Term thromboembolic risk in patients with postoperative atrial fibrillation after coronary artery bypass graft surgery and patients with nonvalvular atrial fibrillation. JAMA Cardiol 2018;3:417-24.

18 Chen AY, Sokol SS, Kress JP, et al. New-Onset atrial fibrillation is an independent predictor of mortality in medical intensive care unit patients. Ann Pharmacother 2015;49:523-7.

19 Brinkman S, de Jonge E, Abu-Hanna A, et al. Mortality after hospital discharge in ICU patients. Crit Care Med 2013;41:1229-36.

20 Christian S-A, Schorr C, Ferchau L, et al. Clinical characteristics and outcomes of septic patients with new-onset atrial fibrillation. $J$ Crit Care 2008;23:532-6.

21 Shahreyar M, Fahhoum R, Akinseye O, et al. Severe sepsis and cardiac arrhythmias. Ann Trans/ Med 2018;6:6. 